\title{
Effects of food form on food intake and postprandial appetite sensations, glucose and endocrine responses, and energy expenditure in resistance trained $v$. sedentary older adults
}

\author{
John W. Apolzan ${ }^{1,2,3}$ t, Heather J. Leidy ${ }^{4}$, Richard D. Mattes ${ }^{1,2}$ and Wayne W. Campbell ${ }^{1,2,3 *}$ \\ ${ }^{1}$ Department of Foods and Nutrition, Purdue University, 700 West State Street, West Lafayette, IN 47907, USA \\ ${ }^{2}$ Ingestive Behavior Research Center, Purdue University, West Lafayette, IN 47907, USA \\ ${ }^{3}$ Center on Aging and the Life Course, Purdue University, West Lafayette, IN 47907, USA \\ ${ }^{4}$ Department of Nutrition and Exercise Physiology, University of Missouri, Columbia, MO 65211, USA
}

(Received 7 October 2010 - Revised 9 February 2011 - Accepted 10 February 2011 - First published online 15 April 2011)

\section{Abstract}

Limited research has suggested that the food form of nutritional supplements (FFNS) and resistance training (RT) influence ingestive behaviour and energy balance in older adults. The effects of the FFNS and RT on acute appetitive, endocrine and metabolic responses are not adequately documented. The present study assessed the effects of the FFNS and RT on postprandial appetite sensations (hunger and fullness), endocrine responses (plasma insulin, cholecystokinin, ghrelin and glucagon-like peptide-1 (GLP-1)), metabolism (glucose, energy expenditure and RER) and food intake (satiation) in older adults. On separate days, eighteen sedentary (Sed) and sixteen RT healthy adults (age 62-84 years) consumed $12.5 \%$ of their energy need as an isoenergetic- and macronutrient-matched solid or beverage. Postprandial responses were assessed over $4 \mathrm{~h}$. No RT $\times$ FFNS interactions were observed for any parameter. Fasting cholecystokinin was higher in the RT $v$. Sed group $(P<0 \cdot 05)$. RT did not influence fullness, but fullness was higher following the solid $v$. beverage intake $(P<0 \cdot 01)$. Neither RT nor FFNS influenced hunger. Glucose and insulin were higher after the solid $v$. beverage intake $(P<0 \cdot 01)$. Ghrelin, GLP-1 and energy expenditure were not different between the RT and FFNS groups. Postprandial cholecystokinin was higher in the RT $v$. Sed group $(P<0 \cdot 01)$ and for solid $v$. beverage $(P<0 \cdot 05)$. RER was lower for solid $v$. beverage $(P<0 \cdot 001)$. Neither RT nor FFNS independently or interactively influenced food intake $2 \mathrm{~h}$ after post-nutritional supplements. In conclusion, RT had little influence on ingestive behaviour. The appetitive and endocrine responses suggested the solid-promoted satiety; however, the FFNS did not alter subsequent food intake.

Key words: Beverages: Thermic effect of food: Insulin: Cholecystokinin

Older individuals experience alterations in physical activity, body composition, appetite and food intake that may lead to a dysregulation of energy balance ${ }^{(1)}$. Typically, there is an increase in daily fullness ${ }^{(2)}$ and a tendency to decrease energy consumption ${ }^{(3,4)}$, leading to anorexia of ageing, lower body weight and sarcopenia. However, most older adults over-consume energy relative to their need, resulting in weight gain $^{(1)}$. It is important to investigate exercise- and diet-related strategies that might help older adults effectively manage body weight because 0.7 and $2.4 \%$ of Americans aged 60-69 and $70+$ years, respectively, are underweight $\left(\right.$ BMI $<18.5 \mathrm{~kg} / \mathrm{m}^{2}$ ) and 75.5 and $65.8 \%$ of older persons aged 60-69 and 70+ years are overweight and obese $\left(\mathrm{BMI} \geq 25 \cdot 0 \mathrm{~kg} / \mathrm{m}^{2}\right)^{(5)}$. Furthermore, sarcopenia and obesity cost the USA approximately $18 \cdot 5^{(6)}$ and $110 \cdot 5$ billion dollars a year ${ }^{(7)}$, respectively.

Older adults expend less energy than younger adults due to sarcopenia and lower levels of physical activity. One common treatment to combat sarcopenia is resistance training (RT), which increases muscle strength, muscle mass and resting energy expenditure ${ }^{(8,9)}$. Limited research in young men has suggested that acute resistance exercise may reduce hunger and ghrelin concentration ${ }^{(10)}$, but the impact of RT on fasting and postprandial appetite and related hormones has been undocumented in older adults.

RT may have an impact on the dietary response of older adults to nutritional supplementation. When sedentary (Sed), frail, elderly men and women consumed a nutritional

Abbreviations: AUC, area under the curve; CCK, cholecystokinin; GLP-1, glucagon-like peptide-1; RT, resistance training/trained; Sed, sedentary.

*Corresponding author: W. W. Campbell, fax +1 7654940674 , email campbellw@purdue.edu

†Present address: Department of Physiology, Georgia Health Sciences University, Augusta, GA 30912, USA. 
supplement in beverage form, they compensated for this energy intake by reducing their habitual food intake ${ }^{(11)}$. Alternately, when RT individuals consumed the dietary supplement, energy compensation was reduced, leading to increased energy intake. These findings suggest that RT may alter ingestive behaviour in older adults.

Food form is also known to influence energy regulation ${ }^{(12,13)}$. Specifically, beverages elicit reduced satiety compared with solid foods in some ${ }^{(14-16)}$ but not all studies ${ }^{(17)}$. Previous research $^{(18)}$ from our laboratory examined appetitive sensations and energy intake following consumption of isoenergetic beverage $v$. solid foods in older adults (age range $50-80$ years $)^{(18)}$. Beverage meal replacement products resulted in greater postprandial hunger and a $13.4 \%$ higher energy intake at the next eating occasion compared with isoenergetic solid meal replacement products ${ }^{(18)}$. Knowledge regarding the mechanisms explaining the differential food form responses is limited, but alterations of postprandial hormone concentrations (i.e. insulin, ghrelin and cholecystokinin (CCK)) and energy expenditure responses have been posited ${ }^{(14,19,20)}$. In the present study, we critically evaluated the acute effects of isoenergetic- and macronutrient-matched beverage and solid supplements on postprandial appetite sensations, endocrine responses, energy expenditure and satiation in Sed $v$. RT older adults. We hypothesised the postprandial appetite responses (decreased hunger, desire to eat and increased fullness) and endocrine responses (increased glucose, insulin, CCK and decreased ghrelin) would be greater following the solid food form and these differential responses would be enhanced with RT.

\section{Methods}

\section{Screening and subjects}

Potential participants responded to newspaper advertisements and flyers recruiting RT and Sed individuals. A phone interview was conducted to estimate physical activity patterns and weight stability. Inclusion criteria for all potential subjects were the following: age $\geq 60$ years; BMI $20-29 \mathrm{~kg} / \mathrm{m}^{2} ;<2 \mathrm{~kg}$ weight change during the previous 6 months; consistent physical activity patterns during the previous 6 months; consume breakfast and lunch; non-smoking; clinically normal blood profile; clinically normal heart function based on resting electrocardiogram; no osteoporosis based on self-report; fasting plasma glucose $\leq 1100 \mathrm{mg} / \mathrm{l}$; no diabetes mellitus; not taking medications known to influence appetite or metabolism; acceptability of test foods. Further inclusion criteria were to be included in the Sed group: participants could not have engaged in RT in the previous 6 months. The RT group was required to have engaged in $\mathrm{RT} \geq 2$ times/week during the previous 6 months.

Initially, nineteen Sed and seventeen RT subjects were in the study, and eighteen (nine males and nine females) and sixteen (seven males and nine females) completed the study, respectively. The present study was conducted according to the guidelines laid down in the Declaration of Helsinki, and all participants were given verbal and written explanations about the study, provided signed informed consent and received a monetary stipend. The study was approved by the Purdue University Biomedical Institutional Review Board and registered at www.clinicaltrials.gov (NCT00798668).

\section{Experimental design and protocol}

A randomised, mixed-model, cross-over design study, incorporating food form (solid $v$. beverage) as a within-subject factor and Sed $v$. RT as a between-subject factor, was performed. Each subject participated in $5 \mathrm{~d}$ of testing. The first day of testing (baseline testing) was used to assess subject characteristics (Table 1). The randomised second and third days were used to assess the effects of food form on most of the study's dependent variables (hunger, fullness, desire to eat, glucose, insulin, ghrelin, CCK, glucagon-like peptide1 (GLP-1), energy expenditure and RER). These days were separated by $48 \mathrm{~h}$. On these days, participants came to the research laboratory after a $12 \mathrm{~h}$ overnight fast. A venous catheter was appropriately placed, and appetite sensations, endocrine responses and energy expenditure were measured at specified times (Fig. 1). During the second week of testing, again volunteers came in on two different days separated by at least $48 \mathrm{~h}$ after a $12 \mathrm{~h}$ overnight fast. These two randomised days were used to assess the effects of food form on satiation.

\section{Baseline testing}

Height was measured to $\pm 0 \cdot 1 \mathrm{~cm}$ using a wall-mounted stadiometer (Holtain Limited, Crymych, Wales, UK). Body weight and body composition were measured by air displacement

Table 1. Subject characteristics and training status for sedentary and resistance trained men and woment

(Mean values with their standard errors)

\begin{tabular}{|c|c|c|c|c|}
\hline & \multicolumn{2}{|c|}{ Sedentary } & \multicolumn{2}{|c|}{$\mathrm{RT}$} \\
\hline & Mean & SE & Mean & SE \\
\hline \multicolumn{5}{|l|}{$\operatorname{Sex}(n)$} \\
\hline Men & \multirow{2}{*}{\multicolumn{2}{|c|}{$\begin{array}{l}9 \\
9\end{array}$}} & \multicolumn{2}{|c|}{7} \\
\hline Women & & & \multicolumn{2}{|c|}{9} \\
\hline Age (years) & 75 & 2 & $69^{\star \star}$ & 1 \\
\hline Weight (kg) & $75 \cdot 4$ & $2 \cdot 2$ & $66 \cdot 9^{\star}$ & $2 \cdot 7$ \\
\hline BMI $\left(\mathrm{kg} / \mathrm{m}^{2}\right)$ & $25 \cdot 7$ & 0.5 & $24 \cdot 0^{\star}$ & 0.6 \\
\hline \multicolumn{5}{|l|}{ Body composition } \\
\hline Body fat (\%) & $34 \cdot 3$ & $2 \cdot 4$ & $31 \cdot 8$ & $2 \cdot 2$ \\
\hline FFM (kg) & $25 \cdot 7$ & 1.8 & $21 \cdot 1$ & 1.6 \\
\hline \multicolumn{5}{|l|}{ Physical activity } \\
\hline VAI units/month $\ddagger$ & $10 \cdot 8$ & $3 \cdot 4$ & $40 \cdot 0^{\star *}$ & $3 \cdot 3$ \\
\hline $\mathrm{h} / \mathrm{d} \ddagger$ & 3.6 & 0.7 & 4.6 & 0.5 \\
\hline $\mathrm{kJ} / \mathrm{d} \S$ & 1138 & 117 & 1778 & 138 \\
\hline $\begin{array}{l}\text { Total maximum } \\
\text { strength }(\mathrm{kg} / \mathrm{kg} \text { FFM)\| }\end{array}$ & $6 \cdot 7$ & 0.3 & $8 \cdot 3^{\star \star}$ & 0.3 \\
\hline
\end{tabular}

$\mathrm{RT}$, resistance training; VAI, vigorous activity index; FFM, fat-free mass

Mean values were significantly different between the groups: ${ }^{\star} P<0.05,{ }^{\star \star} P \leq 0.001$.

† One-way ANOVA comparing sedentary $v$. RT.

$\ddagger$ Estimated from the Yale Physical Activity Questionnaire.

$\S$ Measured from the Caltrac ${ }^{\mathrm{TM}}$ Activity Monitor (Body Flex X-Max).

|l Maximum strength: sum of one-repetition maximum-seated row, seated chest press, leg extension, leg curl and leg press exercises divided by kg of FFM. 
Solid or beverage nutritional supplement

$(12.5 \%$ total daily energy intake)

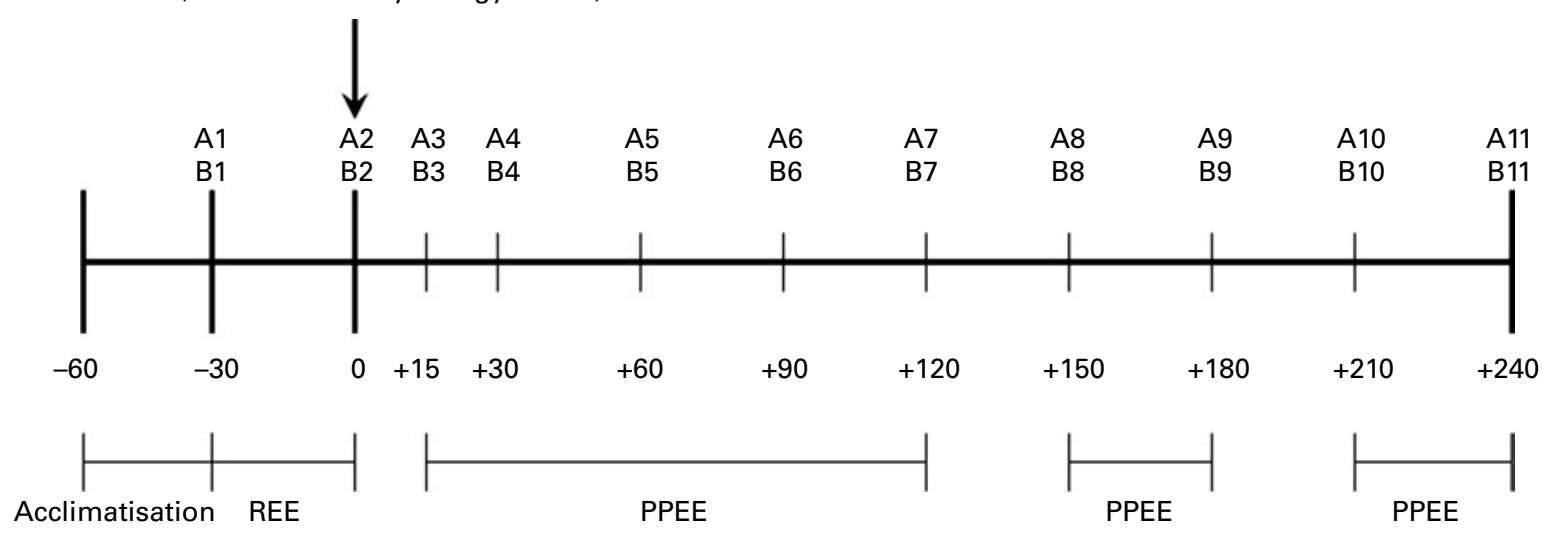

Fig. 1. Timeline of nutritional supplement tests. Percentage of total energy intake is basal energy need (computed using the Harris-Benedict equation) multiplied by an activity factor of 1.5. A, appetite assessment (hunger, fullness and desire to eat); B, blood draw (glucose, insulin, ghrelin, cholecystokinin, glucagon-like peptide-1); REE, fasting resting energy expenditure; PPEE, postprandial REE (thermic effect of feeding).

plethysmography (Bod Pod; Life Measurement, Inc., Concord, CA, USA ${ }^{(21)}$. Fat mass and fat-free mass were estimated from body density using the two-compartment Siri equation ${ }^{(22)}$. BMI was calculated as weight divided by height squared $\left(\mathrm{kg} / \mathrm{m}^{2}\right)$. Maximum strength (one-repetition maximum) was assessed on five pieces of resistance exercise equipment (Keiser Sports Health Equipment Company, Fresno, CA, USA). Lower body (leg extension, seated leg curl and leg press), upper body (upper back (seated row) and seated chest press) and total strength were computed to be the sum of these maximal strength values and are reported as total $\mathrm{kg}$ lifted divided by $\mathrm{kg}$ of fat-free mass.

The Yale Physical Activity Questionnaire was used to estimate hours of habitual physical activity and a vigorous activity index ${ }^{(23)}$. The vigorous activity index was determined by multiplying a frequency score (not at all, $0 ; 1-3$ times/month, 1; 1-2 times/week, 2; 3-4 times/week, 3; $5+$ times/week, 4) by a duration score (not applicable, 0; 10-30 min, 1; 31-60 min, 2; $60+\min , 3)$ and multiplying again by a weighting factor (vigorous, 5; leisurely, 4; moving, 3; standing, 2 ; sitting, 1) ${ }^{(23)}$. On $3 \mathrm{~d}$ (two weekdays and one weekend day), each subject's energy expenditure as physical activity $(\mathrm{kJ} / \mathrm{d})$ was assessed using a Caltrac ${ }^{\mathrm{TM}}$ Activity Monitor (Body Flex X-Max, Van Nuys, CA, USA) worn during waking hours ${ }^{(24)}$.

Also during baseline testing, each subject completed a taste test of the nutritional supplements, rating the palatability (pleasantness) of the solid and beverage using a scale from 1 to 9 (1, extremely unpleasant; 9, extremely pleasant).

\section{Nutritional supplement feeding response tests}

Each participant's total energy need was calculated to equal 1.5 times their estimated resting energy expenditure ${ }^{(25)}$, which was determined using the sex-specific Harris-Benedict equations ${ }^{(26)}$. Previously, RT has been shown not to increase daily energy requirements ${ }^{(27)}$ compared with Sed older individuals. On study days 2, 3, 4 and 5, each subject consumed test supplements that contained $12.5 \%$ of their total energy need (1.08 (SE 0.03); 0.84-1.42 MJ) in either solid (hardness
$1012 \mathrm{~g}$, Texture Analyzer (TA-TX2; Texture Technologies Corporation, Scarsdale, NY, USA) or beverage form (viscosity $21.5 \mathrm{cPs}$, Brookfield Rheometer (RVDV); Brookfield Corporation, Middleboro, MA, USA) with approximately $89 \mathrm{ml}$ $(3 \mathrm{Oz})$ of water for each treatment. After the beverage was consumed, the participants were instructed to rinse the bottle with approximately $89 \mathrm{ml}$ of water and to consume the rinse. By design, the non-commercially available test supplements contained comparable energy and macronutrients (Table 2). A baseline (fasting) blood sample was taken (Table 3) and an appetite questionnaire was completed. At time 0 , the subjects began to consume the test supplement simultaneous with the blood draw. The participants were given $15 \mathrm{~min}$ to consume each test supplement.

\section{Appetite}

At the time points corresponding with each blood draw (Fig. 1), the following appetite-related questions ${ }^{(28)}$ were

Table 2. Total energy and macronutrient composition of solid and beverage treatments

(Mean values with their standard errors for the sedentary and resistance trained groups combined, $n$ 34)

\begin{tabular}{|c|c|c|c|c|}
\hline & \multicolumn{2}{|c|}{ Solid } & \multicolumn{2}{|c|}{ Beverage } \\
\hline & Mean & SE & Mean & SE \\
\hline \multicolumn{5}{|l|}{ Testing supplement } \\
\hline Energy (MJ) & 1.08 & 0.03 & 1.08 & 0.03 \\
\hline Weight (g) & $62 \cdot 8$ & 1.4 & $292 \cdot 2$ & $6 \cdot 4$ \\
\hline \multicolumn{5}{|c|}{ Macronutrient composition } \\
\hline \multicolumn{5}{|c|}{ Total energy (\%) } \\
\hline Carbohydrate & \multicolumn{2}{|c|}{54} & \multicolumn{2}{|c|}{54} \\
\hline Protein & \multicolumn{2}{|c|}{21} & \multicolumn{2}{|c|}{21} \\
\hline Fat & \multirow{2}{*}{\multicolumn{2}{|c|}{25}} & \multicolumn{2}{|c|}{25} \\
\hline g/Supplement & & & & \\
\hline Carbohydrate & 35 & 1 & 35 & 1 \\
\hline Sugar & 19 & 1 & 23 & 1 \\
\hline Fibre & 0 & 0 & 0 & 0 \\
\hline Protein & 14 & 0 & 14 & 0 \\
\hline Fat & 7 & 0 & 7 & 0 \\
\hline
\end{tabular}


Table 3. Values for the fasting appetite glucose and endocrine compounds in sedentary ( $n$ 18) $\dagger$ and resistance trained (RT, $n$ 16) $\ddagger$ subjects\|

(Mean values with their standard errors)

\begin{tabular}{|c|c|c|c|c|}
\hline \multirow[b]{2}{*}{ Parameters } & \multicolumn{2}{|c|}{ Sedentary } & \multicolumn{2}{|c|}{$\mathrm{RT}$} \\
\hline & Mean & SE & Mean & SE \\
\hline \multicolumn{5}{|c|}{ Fasting appetite sensations§ } \\
\hline Fullness (AU) & 3 & 0 & 3 & 1 \\
\hline Hunger (AU) & 6 & 1 & $4^{*}$ & 1 \\
\hline Desire to eat $(\mathrm{AU})$ & 6 & 1 & $4^{*}$ & 1 \\
\hline \multicolumn{5}{|c|}{ Fasting glucose and endocrine values } \\
\hline Glucose (mmol/l) & $5 \cdot 22$ & $0 \cdot 11$ & 5.47 & $0 \cdot 10$ \\
\hline Insulin $(\mu \mathrm{g} / \mathrm{l})$ & 0.28 & 0.05 & 0.30 & 0.06 \\
\hline Ghrelin $(\mu \mathrm{g} / \mathrm{l})$ & 1.98 & 0.21 & $2 \cdot 36$ & 0.35 \\
\hline CCK $(\mu \mathrm{g} / \mathrm{l})$ & 0.62 & 0.08 & $0 \cdot 71^{*}$ & 0.08 \\
\hline GLP-1 ( $\mu \mathrm{g} / \mathrm{l})$ & 0.31 & 0.03 & 0.31 & 0.04 \\
\hline
\end{tabular}

CCK, cholecystokinin; GLP-1, glucagon-like peptide-1.

${ }^{*}$ Mean values were significantly different between the groups $(P<0.05)$

† Nine males and nine females.

$\ddagger$ Seven males and nine females.

$\S$ The lower anchor for the 13-point category scale was 'not at all' (1) and the upper anchor was 'extremely' (13).

|l For statistics, see the Statistical analyses section.

asked; 'How strong is your: feeling of hunger; feeling of fullness; desire to eat?' Each response was recorded on a paper that had a 13-point category scale for each question ${ }^{(16)}$. The subject circled the dash that corresponded with their perception at the moment. The lower anchor ${ }^{(1)}$ was 'not at all' and the upper anchor ${ }^{(13)}$ was 'extremely'.

\section{Endocrine testing}

During each testing period, eleven blood samples were taken (Fig. 1) and immediately placed into blood collection tubes containing potassium EDTA (Becton, Dickinson and Company, Franklin Lakes, NJ, USA). Tubes were kept on ice until they were centrifuged at $4^{\circ} \mathrm{C}$ for $15 \mathrm{~min}$ at $3000 \mathrm{~g}$. Aliquots of plasma were stored at $-80^{\circ} \mathrm{C}$ until thawed for analyses. Plasma glucose concentration was measured by enzymatic colorimetry, using an oxidase method on a COBAS Integra 400 analyser (Roche Diagnostic Systems, Indianapolis, IN, USA). Plasma insulin concentration was measured by an electrochemiluminescence immunoassay method on the Elecsys 2010 analyser (Roche Diagnostic Systems). Total plasma ghrelin, $\mathrm{CCK}_{26-33}$ and $\mathrm{GLP}_{-1} 1_{7-36}$ were analysed through enzyme immunoassay techniques, following the manufacturer's standard protocol (Phoenix Pharmaceuticals, Inc., Burlingame, CA, USA). All samples were run in duplicate and each individual's samples were analysed on the same day within the same assay.

\section{Metabolic testing}

Indirect calorimetry was used to measure resting energy expenditure in the fasting and postprandial states (MedGraphics Cardiopulmonary Diagnostics Systems; MedGraphics Corporation, St Paul, MN, USA). Fasting-state energy expenditure was measured for $30 \mathrm{~min}$ before supplement consumption. Following the supplement, postprandial energy expenditure was periodically measured for three time intervals $(+15$ to $+120 \mathrm{~min} ;+150$ to $+180 \mathrm{~min}$; +210 to $+240 \mathrm{~min}$ ). Non-protein energy expenditure was estimated using the Weir equation ${ }^{(29)}$ and non-protein RER was calculated.

\section{Food intake}

On study days 4 and 5, volunteers were seated $60 \mathrm{~min}$ before consuming the test supplements. The protocol was designed to be similar to days 2 and 3 . At $-50,-40$ and $-30 \mathrm{~min}$, three baseline appetite questionnaires (see above) were given. Then while receiving the test supplement, the participants completed an appetite questionnaire. Questionnaires were also completed at 15, 30, 60, 90, 120, 150 and $180 \mathrm{~min}$. At $120 \mathrm{~min}$ after consuming the supplement, the participants were presented with a bowl of hot oatmeal. They were asked to consume the oatmeal to a 'comfortable level of fullness'. Each bowl contained rolled oats $(120 \mathrm{~g}), 2 \%$ reduced fat milk (75 g), brown sugar ( $24 \mathrm{~g}$ ), salt ( $1 \mathrm{~g})$ and water $(550 \mathrm{~g})$. This represented three commercial servings. The total amounts consumed (weighed to the nearest $0 \cdot 1 \mathrm{~g}$ ) were evaluated as an index of satiation.

\section{Diversionary task}

To minimise bias and not declare the true purpose of the study, several mental diversionary tasks were included in the protocol. They were performed after the appetite questionnaires were completed at $-50,15,90$ and $150 \mathrm{~min}$. At -50 (practice) and $90 \mathrm{~min}$, participants were asked to take eyehand coordination and memory tests using an online computer game, Escapa ${ }^{(30)}$. At 90 min, they were given twelve optical illusions and asked to document what was observed first. Finally, at $150 \mathrm{~min}$, participants had $45 \mathrm{~s}$ to circle as many of the letter ' $\mathrm{S}$ ' as possible on two pages with a random combination of letters.

\section{Statistical analyses}

All values are reported as means with their standard errors. For subject characteristic data, differences between the Sed and RT groups were assessed using one-way ANOVA. After adjusting the postprandial responses for the corresponding fasting values (i.e. expressing the data as a change from baseline), area under the curve (AUC) was calculated using the trapezoidal method. After all preliminary calculations, if needed, based on the Shapiro-Wilk test, data were normalised using a log or square root transformation to approximate a normal distribution. Statistical evaluation of subject characteristic data revealed differences between groups for age and BMI (Table 1). Also, since the initiation of this project, a growing body of emerging research has suggested that sex influences appetitive and endocrine responses, especially insulin and ghrelin ${ }^{(31-35)}$. Therefore, sex, age and BMI were included in the statistical analyses. Note that a priori hypotheses were not generated based on age, BMI and sex. Repeated measures with 
random subject effects were performed using the PROC MIXED model. Fixed effects included the following: food form; RT status; sex; time; age; BMI. Interactions were initially examined among food form, RT status and sex. Then, a backward approach was taken to determine the smallest (best) Akaike information criterion for the model. Leastsquare mean was used to determine treatment effects. The Tukey-Kramer test was used for multiple comparisons. The correlations between fat-free mass and ghrelin concentrations were established using the partial correlation coefficient controlling for RT status, sex and age, and performed according to the previous studies by Tai et $a l^{(36)}$ and Bertoli et $a l^{(37)}$. All data are presented without statistical transformation, but the statistics are reported on the transformed data. The criterion for statistical significance was set at $P<0 \cdot 05$. Statistical evaluations were performed using SAS Statistical Discovery Software (version 9.1; SAS Institute, Cary, NC, USA).

\section{Results}

\section{Day 1: subject characteristics/hedonics}

Subjects ranged in age from 62 to 84 years. The RT group was younger than the Sed group $(P<0 \cdot 01$; Table 1$)$ and had lower body weight $(P<0.05)$ and BMI $(P<0.05)$. Height, body fat percentage and fat-free mass were not different between the groups. Total body strength was higher in the RT $v$. Sed groups $(P<0 \cdot 01)$. The RT group also had greater energy expenditure due to physical activity $(P<0.01)$ and a greater amount of vigorous physical activity $(P<0.01)$ compared with the Sed group. Training status of the subjects did not have an impact on palatability, but the solid supplement was more palatable than the beverage (solid 7 (SE 0), beverage 6 (SE 0); $P<0.05$ ).

\section{Days 2 and 3: food form and appetitive, endocrine and} metabolic responses

Appetite. Baseline appetite values are shown in Table 3. The changes in appetite sensations during the $4 \mathrm{~h}$ period are shown in Fig. 2 and Table 4 . No training status $\times$ food form interactions were observed for the appetitive responses. Postprandial fullness AUC was not different with regard to training status, but was higher in the solid $v$. beverage treatment (Fig. 2(a); $P<0.01$ ). No differences in postprandial hunger or desire-to-eat AUC were observed with respect to training status or food form (Fig. 2(B) and 2(C)).

Endocrine testing. The fasting concentrations of glucose and hormones are shown in Table 3. The RT group had a higher fasting plasma CCK concentration $(P<0.05)$. The changes in glucose and endocrine responses during the $4 \mathrm{~h}$ period are shown in Fig. 3 (a)-(e). No training status $\times$ food form interactions were observed with postprandial glucose or endocrine responses. No training status differences were seen with postprandial glucose or insulin (Table 4). Postprandial glucose and insulin were higher following the solid $v$. beverage test supplement $(P<0.01$ and $<0 \cdot 01$, respectively). No difference in postprandial ghrelin was observed with
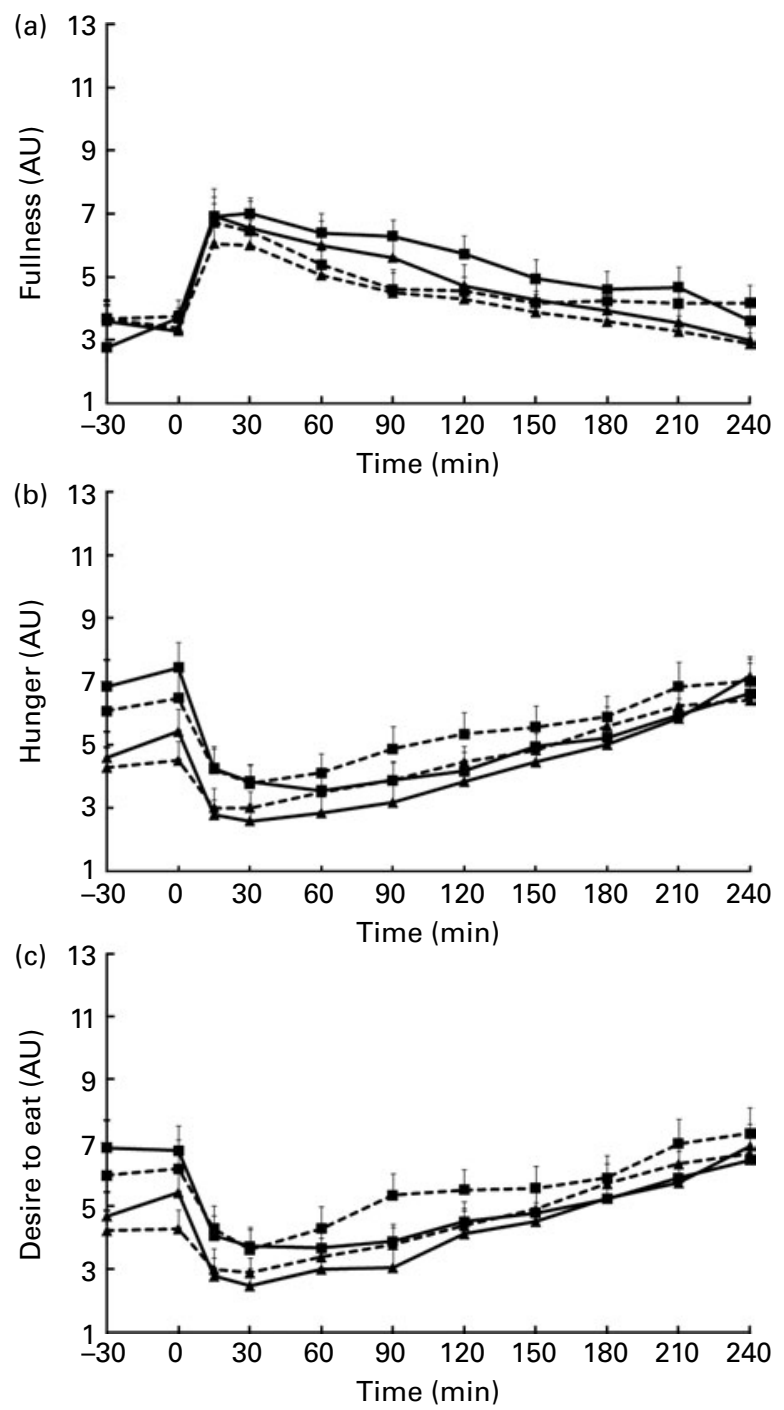

Fig. 2. Appetitive sensations and plasma glucose and endocrine responses for the sedentary and resistance trained (RT) males and females after beverage and solid supplement consumption. Values are means for eighteen sedentary and sixteen RT subjects for appetitive sensations and eighteen sedentary and fifteen RT subjects for glucose and endocrine responses, with standard errors represented by vertical bars. (a) RT status did not influence postprandial fullness. Postprandial fullness was lower after the beverage $v$. solid was consumed (218 (SE 94) v. 475 (SE 96) arbitrary units $(A U) \times 240 \mathrm{~min} ; P<0.01$ ). (b) No RT status or food form differences were seen with hunger. (c) No RT status or food form differences were seen with desire to eat. $-\mathbf{\leftarrow}$, Solid (trained); $-\mathbf{A}-$, beverage (trained); $-\mathbf{-}$, solid (sedentary); -e-, beverage (sedentary).

training status or food form. The CCK concentration over the $4 \mathrm{~h}$ period was elevated in the RT $v$. Sed individuals $(P<0.01)$ and higher following the solid $v$. beverage test supplement $(P<0 \cdot 05)$. Postprandial GLP-1 AUC did not differ between the training status groups or food form stimuli.

Metabolic testing. No training status $\times$ food form interactions were observed with postprandial energy expenditure or RER responses. Postprandial energy expenditure over the $4 \mathrm{~h}$ period was not affected by training status or food form (data not shown; RT 33.22 (SE 27.61) kJ/min $\times 240 \mathrm{~min}$ $(7.94(\operatorname{se} 6.60) \mathrm{kcal} / \mathrm{min} \times 240 \mathrm{~min}) \quad v$. Sed $43.63(\operatorname{se~} 26.56)$ 
Table 4. Postprandial area under the curve responses for appetite, glucose and endocrine after consuming beverage or solid food in sedentary (Sed) and resistance trained (RT) men and women

(Mean values with their standard errors)

\begin{tabular}{|c|c|c|c|c|c|c|c|c|}
\hline \multirow[b]{3}{*}{ Parameters } & \multicolumn{4}{|c|}{ Solid } & \multicolumn{4}{|c|}{ Beverage } \\
\hline & \multicolumn{2}{|c|}{ Sed } & \multicolumn{2}{|c|}{ RT } & \multicolumn{2}{|c|}{ Sed } & \multicolumn{2}{|c|}{ RT } \\
\hline & Mean & SE & Mean & SE & Mean & SE & Mean & SE \\
\hline \multicolumn{9}{|c|}{ Appetite sensations $(A U \times 240 \mathrm{~min}) \ddagger$} \\
\hline Fullness & 644 & 139 & 286 & 119 & 256 & 92 & $175^{\star \star}$ & 149 \\
\hline Hunger & 540 & 175 & -83 & 153 & -114 & 154 & -127 & 173 \\
\hline $\mathrm{DE}$ & -522 & 166 & -116 & 114 & -145 & 150 & 25 & 119 \\
\hline \multicolumn{9}{|c|}{ Glucose and endocrine responses\| } \\
\hline Glucose (mmol/l × $240 \mathrm{~min})$ & 9.52 & $19 \cdot 6$ & $52 \cdot 6$ & $25 \cdot 4$ & $-12 \cdot 3$ & $12 \cdot 1$ & $-11 \cdot 0^{\star \star}$ & $22 \cdot 4$ \\
\hline Insulin $(\mu \mathrm{g} / \mathrm{l} \times 240 \mathrm{~min})$ & 131.0 & $18 \cdot 72$ & $100 \cdot 8$ & $10 \cdot 65$ & 88.28 & $12 \cdot 12$ & $63.04^{\star \star}$ & 6.615 \\
\hline Ghrelin $(\mu \mathrm{g} / \mathrm{l} \times 240 \mathrm{~min})$ & -4.72 & 24.9 & $60 \cdot 3$ & 33.3 & $-30 \cdot 1$ & $46 \cdot 2$ & $-27 \cdot 9$ & $51 \cdot 6$ \\
\hline $\mathrm{CCK}(\mu \mathrm{g} / / \times 240 \mathrm{~min})$ & $28 \cdot 7$ & 12.6 & 39.1 & $12 \cdot 6$ & -4.39 & 10.5 & $18 \cdot 9^{\star \star} \dagger$ & 14.8 \\
\hline GLP-1 $(\mu \mathrm{g} / \mathrm{l} \times 240 \mathrm{~min})$ & $2 \cdot 80$ & 3.13 & 4.65 & 3.49 & $1 \cdot 11$ & 3.77 & 8.15 & 5.45 \\
\hline
\end{tabular}

$\mathrm{AU}$, arbitrary units; $\mathrm{DE}$, desire to eat; CCK, cholecystokinin; GLP-1, glucagon-like peptide-1.

Mean values were significantly different between the treatment groups: ${ }^{*} P<0.05,{ }^{*} P \leq 0.01$.

Mean values were significantly different between the training status groups $(\dagger P<0.05)$.

$\ddagger$ For the appetite sensations, eighteen sedentary (nine males and nine females) and sixteen resistance trained (seven males and nine females).

$\S$ For the endocrine responses, eighteen sedentary (nine males and nine females) and fifteen resistance trained (seven males and nine females).

$\mathrm{kJ} / \mathrm{min} \times 240 \mathrm{~min}(10.43(\mathrm{sE} 6.35) \mathrm{kcal} / \mathrm{min} \times 240 \mathrm{~min}) ;$ solid $34.60(\mathrm{se} 28 \cdot 86) \mathrm{kJ} / \mathrm{min} \times 240 \mathrm{~min}(8.27 \quad(\mathrm{se} \quad 6.90) \mathrm{kcal} /$ $\min \times 240 \mathrm{~min}) v$. beverage $46.19(\mathrm{sE} 23.63) \mathrm{kJ} / \mathrm{min} \times 240 \mathrm{~min}$ $(11.04(\mathrm{SE} 5.65) \mathrm{kcal} / \mathrm{min} \times 240 \mathrm{~min})$. Postprandial RER AUC was unaffected by training status, but lower following the solid (data not shown; $0.04(\mathrm{se} 0.01) \times 240 \mathrm{~min}) v$. beverage test supplement $(0.05$ (SE 0.01$) \times 240 \mathrm{~min} ; P<0.001)$.

Fat-free mass and ghrelin correlations. Fat-free mass was not associated with fasting or postprandial ghrelin (fasting $r-0 \cdot 070$; postprandial $r$ 0.004).

\section{Days 4 and 5: food form and satiation}

Appetite. No training status $\times$ food form interactions were observed for the appetitive responses. Postprandial fullness, hunger and desire to eat were unaffected by training status (data not shown; fullness, RT 276 (SE 89) $v$. Sed 198 (SE 49); hunger, $\mathrm{RT}-277$ (SE 68) v. Sed -202 (SE 43); desire to eat, $\mathrm{RT}-239$ (SE 71) $v$. Sed -178 (SE 51)) but fullness was higher in the solid $v$. beverage (302 (SE 47) v. 167 (SE 56), respectively; $P<0.01$ ) and hunger and desire to eat were lower in the solid $v$. beverage treatments (hunger, solid -260 (SE 47) $v$. beverage -186 (SE 53); desire to eat, solid -237 (se 44) $v$. beverage -175 (SE 47); $P<0 \cdot 05$ ).

Food intake. No training status $\times$ food form interactions were observed with food intake. Satiation was not affected by training status or food form (data not shown; RT 333.7 (SE 26.3) $v$. Sed 303.9 (SE 25.4) g; solid 329.8 (SE 22.9) $v$. beverage $311 \cdot 5$ (SE 20.4) g).

\section{Discussion}

The present study compared the appetitive, metabolic and endocrine responses between RT and Sed older individuals following the consumption of energy- and macronutrientmatched beverage and solid nutritional supplements. Contrary to our hypothesis, RT did not influence postprandial appetitive, metabolic or endocrine responses to food form (i.e. there was no RT status $\times$ food form interactions). However, the RT group had reduced fasting hunger and desire to eat and increased fasting CCK. The findings that the nutritional supplement in beverage form elicited lower fullness along with decreased glucose, insulin and CCK responses compared with the solid food form coincides with most $^{(14-16,38,39)}$, but not all ${ }^{(17)}$ published research indicating that beverages elicit weaker satiety sensations than solid foods. However, in contrast to our hypothesis, the findings also suggest no differential food form effect over $4 \mathrm{~h}$ on hunger, desire to eat or GLP-1. Recently, Mourao et al. ${ }^{(38)}$ also suggested that solid food form resulted in lower postprandial feelings of fullness compared with beverages but did not affect feelings of hunger. The findings that food form affected fullness but not hunger are plausible since these are different dimensions of appetite (i.e. previously CCK has been shown to reduce meal size, which demonstrates satiation but not satiety). Overall, the weaker dietary compensation previously observed with beverages ${ }^{(16,18,38)}$ may be attributable to the differential glucose and endocrine responses they elicited, but in these older individuals, no food intake differences were observed. We consider the provision of the nutritional supplement, $12.5 \%$ of each subject's estimated energy need and not matched for volume, as practically important because this amount corresponds with approximately a single serving of supplement: one bar (solid) and one drink (beverage).

Our finding of no differential response for postprandial energy expenditure in RT $v$. Sed older adults is consistent with findings in younger adults ${ }^{(40)}$. The present finding that food form did not influence postprandial energy expenditure contrasts with the report that postprandial energy expenditure was approximately $85 \%$ higher when young men consumed a $2 \cdot 6 \mathrm{MJ}$ (approximately $615 \mathrm{kcal}$ ) meal as whole foods (solid-liquid), compared with when the same food items were homogenised with water and 

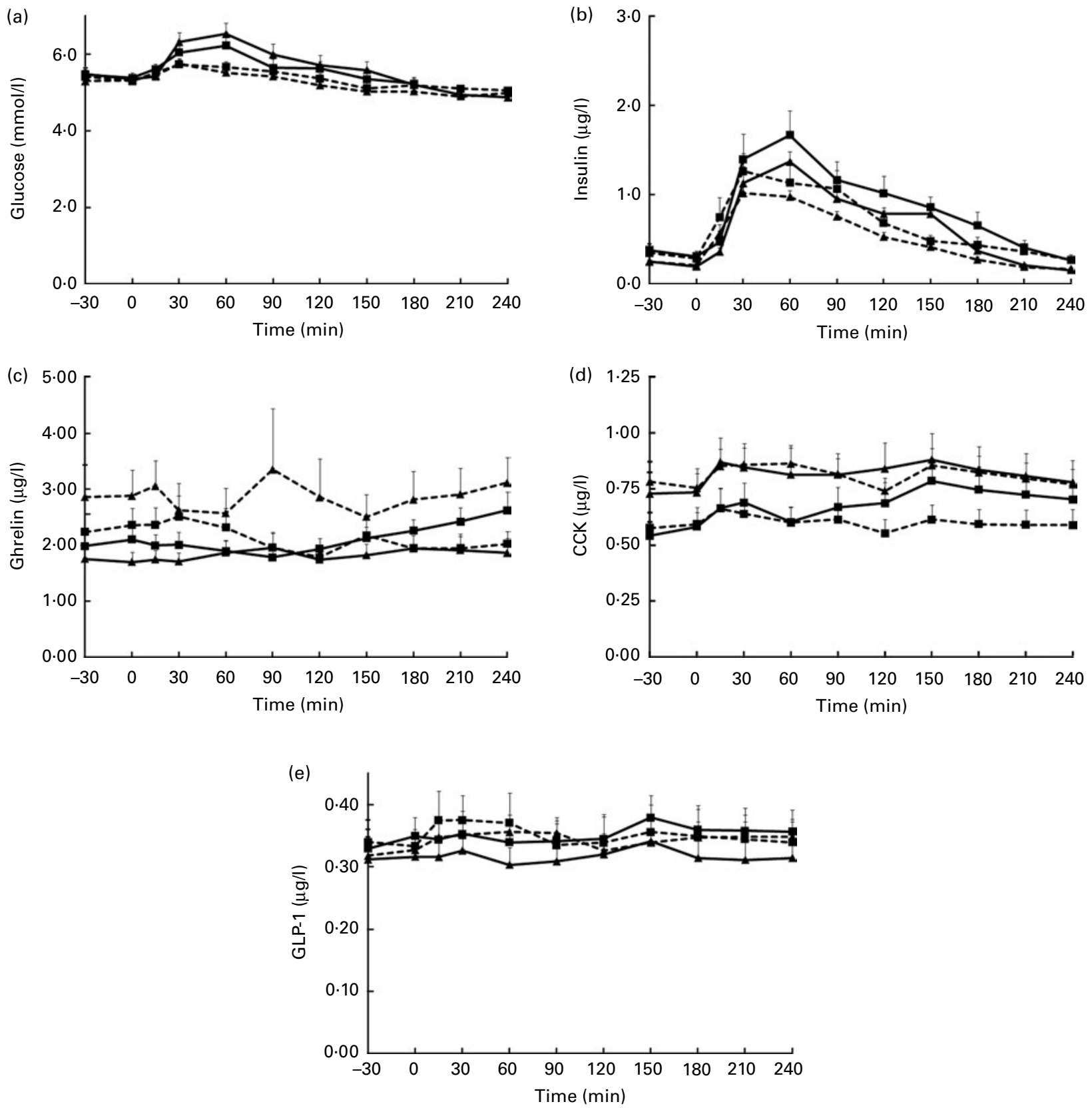

Fig. 3. Plasma glucose and endocrine responses for the sedentary and resistance trained (RT) males and females after beverage and solid supplement consumption. Values are means for eighteen sedentary and fifteen RT subjects, with standard errors represented by vertical bars. (a) RT status did not affect plasma glucose. Beverages decreased plasma glucose area under the curve (AUC) $v$. solids (-2660 (SE 2400) v. 5030 (SE 2920) $\mathrm{mg} / \mathrm{l} \times 240 \mathrm{~min}$; $P<0.01$ ). (b) No training status effects were observed with plasma insulin. Beverages decreased plasma insulin AUC v. solids (12978 (SE 1244) v. 19522 (SE $1897 \mathrm{pmol} / \mathrm{l} \times 240 \mathrm{~min}$; $P \leq 0.001)$. (c) No training status or food form differences were observed with ghrelin. (d) Training increased cholecystokinin (CCK) AUC $v$. sedentary (28.97 (SE 12.70) v. 12.16 (SE 7.73) $\mathrm{ng} / \mathrm{ml} \times 240 \mathrm{~min} ; P<0.01$ ) and beverages decreased CCK AUC levels compared with solids (6.19 (SE 8.91) $v$. 33.42 $(\mathrm{SE} 8.86) \mathrm{ng} / \mathrm{ml} \times 240 \mathrm{~min} ; \boldsymbol{P}<0.05)$. (e) RT status and food form did not affect glucagon-like peptide-1 AUC. $\_$-, Solid (trained); - $\_-$, beverage (trained); $\rightarrow-$, solid (sedentary); - - beverage (sedentary).

consumed as a viscous suspension ${ }^{(20)}$. Both of these studies contrast with the observation that postprandial energy expenditure was $54 \%$ higher after eight healthy, normal-weight young men consumed a $2 \cdot 1 \mathrm{MJ}$ (approximately $500 \mathrm{kcal}$ ) solid meal compared with a liquid meal of similar macronutrient composition $^{(41)}$. Furthermore, the interpretation of these disparate results is complicated by multifarious factors, including energy content and macronutrient distribution of the test meals; glycaemic and insulinaemic responses; gastrointestinal transit time and absorption; and subjects' sex and age ${ }^{(1,42-46)}$. Peracchi et al. ${ }^{(20)}$ did not evaluate RER. In the present study, RER was lower after solid consumption, suggesting higher fat oxidation, whereas beverage consumption resulted in higher carbohydrate oxidation and thus lower fat oxidation. 
The higher postprandial glucose, insulin and CCK AUC following the solid $v$. beverage nutritional supplement might be the result of increased (slower) gastric transit time. Specifically, solid foods appear to elicit a slower gastrointestinal transit time than beverages ${ }^{(47-49)}$, which may result in a different absorption profile. Within physiological ranges, higher CCK and GLP-1 inhibit gastric emptying ${ }^{(50,51)}$. Our data follow this pattern since solids elicited a greater CCK response than beverages. GLP-1 secretion did not vary between solid and beverage test supplements. Previous research provided mixed results regarding gastrointestinal transit time and ageing $^{(52-55)}$ and suggested that, in younger individuals, beverages have faster gastric emptying time ${ }^{(56,57)}$ and orocaecal transit time than solids ${ }^{(58)}$.

RT increases fat-free mass due to muscle hypertrophy in older adults ${ }^{(59)}$, and fat-free mass and appendicular muscle mass were shown to be positively correlated with fasting ghrelin in healthy younger, older and elderly subjects ${ }^{(36,37)}$. In contrast to these findings, our RT and Sed subjects did not exhibit a significant correlation between fat-free mass and ghrelin. Tai et $a{ }^{(36)}$ studied adults of all ages, 22-82 years, while the present study and Bertoli et $a l^{(37)}$ studied older adults. The 60-year age range by Tai et al. may have resulted in a broader distribution of data contributing to a significant correlation. Differences in the measurement of fat-free mass might also have contributed to the apparently disparate findings among studies. Tai and Bertoli et al. measured appendicular muscle mass using dual-energy X-ray absorptiometry ${ }^{(36,37)}$, while the present study measured whole-body fat-free mass using plethysmography. Appendicular muscle mass is a strong predictor of fasting ghrelin concentration ${ }^{(36,37)}$. This parameter was not measured in the present study.

One of the strengths of the present study was the recruitment of older people who habitually performed RT. Currently, approximately $11 \%$ of adults aged 65 years and older in the $\mathrm{USA}^{(60)}$ engage in this mode of exercise because it is encouraged for older people to retain and enhance muscle mass, strength, physical function and health indices associated with the metabolic syndrome. The $1.7 \mathrm{~kg} / \mathrm{m}^{2}$ BMI difference between the RT and Sed groups may be considered a weakness, but this subtle difference was accounted for statistically. The appetite ratings appear relatively low for the fasted state, which may be due to the use of the equal interval appetite scale (compared with the labelled magnitude scale) ${ }^{(61)}$. Also, appetite questionnaires were examined across groups (between subject) for RT. It is not possible to determine whether all subjects had similar responses at the various intensities $^{(62,63)}$ so caution is warranted when interpreting these results. Lastly, not matching the beverage and solid nutritional supplements for weight or volume might also be considered a weakness. However, we chose to administer the products comparably with how they are consumed commercially. It is perhaps important to note that while the volume of the beverage was greater than the solid, the appetitive responses were consistent with lower satiety.

\section{Conclusions}

Findings from the present study suggest that RT and food form independently, but not synergistically, affect appetitive, metabolic or endocrine responses in older adults. However, the RT effect was limited to fasting and postprandial CCK. None of the results suggest that the beverage was more satiating than the solid. Some, but not all, endocrine responses found the solid to be more satiating than the beverage. The differential glucose, insulin, ghrelin and CCK responses between supplement treatments implicate food form as an important factor influencing energy homeostasis and indicate that energy- and macronutrient-matched nutritional supplements in the solid $v$. beverage form are not equivalent. Although the beverage supplement altered appetitive, endocrine and metabolic responses, the beverage food form did not alter subsequent food intake in this acute laboratory setting. RT and food form should be considered when recommending a weight management strategy to older adults, although they may not affect dietary energy intake.

\section{Acknowledgements}

The authors have no conflict of interest. The authors thank the volunteers for their time and dedication: Arthur Rosen, MD, for providing medical coverage, Douglas Maish, EMT-P, for inserting the catheters and providing other clinical services, Kristin Duke, BS, for assisting with clinical services, and Eunjung Lim, MS, for consulting on statistical analyses. W. W. C. and R. D. M. originated the study, obtained funding and provided supervision of the research. J. W. A. and H. J. L. were involved with the development of the study purpose and design. J. W. A. performed the clinical testing and data analysis. J. W. A. drafted the manuscript and all co-authors contributed to the data interpretation and finalisation of the manuscript. The study was supported by a NIH R01 AG021911 and the study supplements were provided by The Solae Company. Support for H. J. L. was provided in part by an Ingestive Behavior Research Center post-doctoral fellowship from Purdue University, and support for J. W. A. was provided in part by a Purdue University Bilsland Fellowship.

\section{References}

1. Roberts SB \& Rosenberg I (2006) Nutrition and aging: changes in the regulation of energy metabolism with aging. Physiol Rev 86, 651-667.

2. Morley JE (1997) Anorexia of aging: physiologic and pathologic. Am J Clin Nutr 66, 760-773.

3. Wilson MM, Purushothaman R \& Morley JE (2002) Effect of liquid dietary supplements on energy intake in the elderly. Am J Clin Nutr 75, 944-947.

4. Vellas BJ, Hunt WC, Romero LJ, et al. (1997) Changes in nutritional status and patterns of morbidity among freeliving elderly persons: a 10-year longitudinal study. Nutrition 13, 515-519.

5. Flegal KM, Graubard BI, Williamson DF, et al. (2005) Excess deaths associated with underweight, overweight, and obesity. JAMA 293, 1861-1867. 
6. Janssen I, Shepard DS, Katzmarzyk PT, et al. (2004) The healthcare costs of sarcopenia in the United States. $J$ Am Geriatr Soc 52, 80-85.

7. Tsai AG, Williamson DF \& Glick HA (2010) Direct medical cost of overweight and obesity in the USA: a quantitative systematic review. Obes Rev (Epublication ahead of print version 6 January 2010).

8. American College of Sports Medicine Position Stand (1998) The recommended quantity and quality of exercise for developing and maintaining cardiorespiratory and muscular fitness, and flexibility in healthy adults. Med Sci Sports Exerc 30, 975-991.

9. Villareal DT, Apovian CM, Kushner RF, et al. (2005) Obesity in older adults: technical review and position statement of the American Society for Nutrition and NAASO. The Obesity Society. Am J Clin Nutr 82, 923-934.

10. Broom DR, Batterham RL, King JA, et al. (2008) The influence of resistance and aerobic exercise on hunger, circulating levels of acylated ghrelin and peptide YY in healthy males. Am J Physiol Regul Integr Comp Physiol 296, R29-R35.

11. Fiatarone MA, O'Neill EF, Ryan ND, et al. (1994) Exercise training and nutritional supplementation for physical frailty in very elderly people. $N$ Engl J Med 330, 1769-1775.

12. Bray GA, Nielsen SJ \& Popkin BM (2004) Consumption of high-fructose corn syrup in beverages may play a role in the epidemic of obesity. Am J Clin Nutr 79, 537-543.

13. Wharton CM \& Hampl JS (2004) Beverage consumption and risk of obesity among Native Americans in Arizona. Nutr Rev 62, 153-159.

14. Tieken SM, Leidy HJ, Stull AJ, et al. (2007) Effects of solid versus liquid meal-replacement products of similar energy content on hunger, satiety, and appetite-regulating hormones in older adults. Horm Metab Res 39, 389-394.

15. Rothacker DQ, Staniszewski BA \& Ellis PK (2001) Liquid meal replacement vs traditional food: a potential model for women who cannot maintain eating habit change. $J \mathrm{Am}$ Diet Assoc 101, 345-347.

16. DiMeglio DP \& Mattes RD (2000) Liquid versus solid carbohydrate: effects on food intake and body weight. Int J Obes Relat Metab Disord 24, 794-800.

17. Almiron-Roig E, Flores SY \& Drewnowski A (2004) No difference in satiety or in subsequent energy intakes between a beverage and a solid food. Physiol Behav 82, 671-677.

18. Stull AJ, Apolzan JW, Thalacker-Mercer AE, et al. (2008) Liquid and solid meal replacement products differentially affect postprandial appetite and food intake in older adults. J Am Diet Assoc 108, 1226-1230.

19. Santangelo A, Peracchi M, Conte D, et al. (1998) Physical state of meal affects gastric emptying, cholecystokinin release and satiety. Br J Nutr $\mathbf{8 0}, 521-527$.

20. Peracchi M, Santangelo A, Conte D, et al. (2000) The physical state of a meal affects hormone release and postprandial thermogenesis. Br J Nutr 83, 623-628.

21. McCrory MA, Gomez TD, Bernauer EM, et al. (1995) Evaluation of a new air displacement plethysmograph for measuring human body composition. Med Sci Sports Exerc 27, $1686-1691$.

22. Siri WE (1956) The gross composition of the body. Adv Biol Med Phys 4, 239-280.

23. Dipietro L, Caspersen CJ, Ostfeld AM, et al. (1993) A survey for assessing physical activity among older adults. Med Sci Sports Exerc 25, 628-642.

24. Melanson EL Jr \& Freedson PS (1995) Validity of the Computer Science and Applications, Inc. (CSA) activity monitor. Med Sci Sports Exerc 27, 934-940.
25. Shetty PS, Henry CJ, Black AE, et al. (1996) Energy requirements of adults: an update on basal metabolic rates (BMRs) and physical activity levels (PALs). Eur J Clin Nutr 50, Suppl. 1, S11-S23.

26. Harris JA \& Benedict FG (1919) A Biometric Study of Basal Metabolism in Man. Washington, DC: Carnegie Institute of Washington.

27. Campbell WW, Kruskall LJ \& Evans WJ (2002) Lower body versus whole body resistive exercise training and energy requirements of older men and women. Metabolism 51, 989-997.

28. Rogers PJ \& Blundell JE (1979) Effect of anorexic drugs on food intake and the micro-structure of eating in human subjects. Psychopharmacology (Berl) 66, 159-165.

29. Weir JB (1949) New methods for calculating metabolic rate with special reference to protein metabolism. J Physiol 109, 1-9.

30. Escapa. http://www3.telus.net/pic_folder/pics/aguanta.htm (accessed 6 February 2011)

31. Carroll JF, Kaiser KA, Franks SF, et al. (2007) Influence of BMI and gender on postprandial hormone responses. Obesity (Silver Spring) 15, 2974-2983.

32. Greenman Y, Golani N, Gilad S, et al. (2004) Ghrelin secretion is modulated in a nutrient- and gender-specific manner. Clin Endocrinol (Oxf) 60, 382-388.

33. Makovey J, Naganathan V, Seibel M, et al. (2007) Gender differences in plasma ghrelin and its relations to body composition and bone - an opposite-sex twin study. Clin Endocrinol (Oxf) 66, 530-537.

34. Davy BM, Van Walleghen EL \& Orr JS (2007) Sex differences in acute energy intake regulation. Appetite 49, 141-147.

35. Hagobian TA, Sharoff CG, Stephens BR, et al. (2009) Effects of exercise on energy-regulating hormones and appetite in men and women. Am J Physiol Regul Integr Comp Physiol 296, R233-R242.

36. Tai K, Visvanathan R, Hammond AJ, et al. (2009) Fasting ghrelin is related to skeletal muscle mass in healthy adults. Eur J Nutr 48, 176-183.

37. Bertoli S, Magni P, Krogh V, et al. (2006) Is ghrelin a signal of decreased fat-free mass in elderly subjects? Eur J Endocrinol 155, 321-330.

38. Mourao DM, Bressan J, Campbell WW, et al. (2007) Effects of food form on appetite and energy intake in lean and obese young adults. Int J Obes (Lond) 31, 1688-1695.

39. Mattes RD (1996) Dietary compensation by humans for supplemental energy provided as ethanol or carbohydrate in fluids. Physiol Behav 59, 179-187.

40. Gilbert JA \& Misner JE (1993) Failure to find increased TEM at rest and during exercise in aerobically trained and resistance trained subjects. Int J Sport Nutr 3, 55-66.

41. Habas ME \& Macdonald IA (1998) Metabolic and cardiovascular responses to liquid and solid test meals. Br J Nutr 79, 241-247.

42. Granata GP \& Brandon LJ (2002) The thermic effect of food and obesity: discrepant results and methodological variations. Nutr Rev 60, 223-233.

43. Kinabo JL \& Durnin JV (1990) Effect of meal frequency on the thermic effect of food in women. Eur J Clin Nutr $\mathbf{4 4}$ 389-395.

44. Kinabo JL \& Durnin JV (1990) Thermic effect of food in man: effect of meal composition, and energy content. Br J Nutr $\mathbf{6 4}$ 37-44.

45. Macdonald I (1984) Differences in dietary-induced thermogenesis following the ingestion of various carbohydrates. Ann Nutr Metab 28, 226-230.

46. Tataranni PA, Larson DE, Snitker S, et al. (1995) Thermic effect of food in humans: methods and results 
from use of a respiratory chamber. Am J Clin Nutr $\mathbf{6 1}$, 1013-1019.

47. v Schonfeld J, Evans DF, Goebell H, et al. (1997) Comparison of the small bowel motor response to solid and liquid meals in man. Digestion 58, 402-406.

48. Siegel JA, Urbain JL, Adler LP, et al. (1988) Biphasic nature of gastric emptying. Gut 29, 85-89.

49. Hinder RA \& Kelly KA (1977) Canine gastric emptying of solids and liquids. Am J Physiol 233, E335-E340.

50. Little TJ, Horowitz M \& Feinle-Bisset C (2005) Role of cholecystokinin in appetite control and body weight regulation. Obes Rev 6, 297-306.

51. Holst JJ (2007) The physiology of glucagon-like peptide 1. Physiol Rev 87, 1409-1439.

52. Horowitz M, Maddern GJ, Chatterton BE, et al. (1984) Changes in gastric emptying rates with age. Clin Sci (Lond) 67, 213-218.

53. Wegener M, Borsch G, Schaffstein J, et al. (1988) Effect of ageing on the gastro-intestinal transit of a lactulosesupplemented mixed solid-liquid meal in humans. Digestion 39, 40-46.

54. Moore JG, Tweedy C, Christian PE, et al. (1983) Effect of age on gastric emptying of liquid-solid meals in man. Dig Dis Sci 28, 340-344.

55. Kupfer RM, Heppell M, Haggith JW, et al. (1985) Gastric emptying and small-bowel transit rate in the elderly. $J \mathrm{Am}$ Geriatr Soc 33, 340-343.
56. Notivol R, Carrio I, Cano L, et al. (1984) Gastric emptying of solid and liquid meals in healthy young subjects. Scand $J$ Gastroenterol 19, 1107-1113.

57. Moore JG, Christian PE \& Coleman RE (1981) Gastric emptying of varying meal weight and composition in man. Evaluation by dual liquid- and solid-phase isotopic method. Dig Dis Sci 26, 16-22.

58. Bennink R, Peeters M, Van den Maegdenbergh V, et al. (1999) Evaluation of small-bowel transit for solid and liquid test meal in healthy men and women. Eur $J \mathrm{NuCl}$ Med 26, 1560-1566.

59. Frontera WR, Meredith CN, O'Reilly KP, et al. (1988) Strength conditioning in older men: skeletal muscle hypertrophy and improved function. J Appl Physiol 64, 1038-1044.

60. Centers for Disease Control and Prevention (2004) Strength training among adults aged $>/=65$ - United States, 2001. Morb Mortal Wkly Rep 53, 25-28.

61. Green BG, Dalton P, Cowart B, et al. (1996) Evaluating the 'Labeled Magnitude Scale' for measuring sensations of taste and smell. Chem Senses 21, 323-334.

62. Bartoshuk LM, Duffy VB, Hayes JE, et al. (2006) Psychophysics of sweet and fat perception in obesity: problems, solutions and new perspectives. Philos Trans R Soc Lond B Biol Sci 361, 1137-1148.

63. Bartoshuk LM, Duffy VB, Green BG, et al. (2004) Valid across-group comparisons with labeled scales: the gLMS versus magnitude matching. Physiol Behav 82, 109-114. 